Medina, Rubén (coord.). Perros habitados por las voces del desierto. Ciudad de México: Editorial Aldus, 2013, 434 pp. ISBN 978-6077742-89-0

\title{
Nibaldo Acero
}

Pontificia Universidad Católica de Chile. Santiago, Chile nibaldo.acero@gmail.com

Oi bien han Sido cada vez más frecuentes los acercamientos desde la críStica literaria al Infrarrealismo, aún no se ha logrado la materialización de un estudio amplio, sistemático y profundizado del mismo. Si se gesta una pesquisa de las publicaciones cuyo objeto haya sido este movimiento de vanguardia, no será difícil de corroborar, como lo hace Rubén Medina -poeta infrarrealista, seleccionador e introductor de esta antología- cierto menoscabo o reductibilidad de parte de las Ciencias Sociales, que ha observado al Infrarrealismo en función de la figura y obra de Roberto Bolaño, suscitando incluso resistencias a considerarlo una vanguardia en sí o una vanguardia aún vigente. Este aspaviento canónico coincide con la manipulación y la utilitarización del Infrarrealismo, resignificándolo como elemento accesorio, paisajístico u ornamental de la prosa de Bolaño, más precisamente de la novela Los detectives salvajes. No obstante, de aquella misma pesquisa también se puede hacer el rescate de reflexiones críticas productivas y significativas sobre esta vanguardia, entre las que destaca la investigación llevada a cabo por la académica argentina Andrea Cobas. Sin embargo, predominan las aproximaciones que han cultivado subterfugios argumentativos, sometiendo al Infrarrealismo exclusivamente a una faena contextual y que en definitiva han aportado más desde el mito que de una reflexión académica, potenciando la resistencia mencionada.

Ante esta suerte de guerra fría de parte de la cultura oficial, Perros habitados por las voces del desierto, que debe su título a un verso del poema 
"Ya lejos de la carretera" de Mario Santiago, instala y echa a andar una antología poética y crítica que en su voluntad estética y de ilustración, se transforma en una obra reivindicativa de este movimiento de ruptura. Su introducción opera como metalectura, apuesta que integra, como se señalaba, un deseo de ilustración, una introspección y la visibilización de una poética tribal. Además, demarca al Infrarrealismo identificando dos claras directrices: por un lado la figura y discurso del poeta Mario Santiago y, por el otro, los de Roberto Bolaño: estrecho ángulo por donde fluyen poderosamente los poetas que integran la «tribu», figura con la que se definen y autoproclaman los poetas infra (en consonancia con el verso de Mario Santiago "... años después seguimos siendo Tribu"). Papasquiaro representa el proyecto infrarrealista consumado, cuya posición acomete unificar decididamente arte y vida, procurando no hacer del arte un oficio y subvirtiendo la marginalidad como su genuino centro, abandonando con ello y por completo un proyecto vinculado a la búsqueda de parcelas de poder. Bolaño por su parte, representa una vertiente mayormente racional, que si bien tampoco se contonea estratégicamente, acercándose o coqueteando con el poder, moviliza su proyecto estético entre el margen y el canon, territorio intempérico donde el escritor hace del arte un oficio, el único a partir de su éxito editorial. Sin embargo, escribe Rubén Medina, a ambos -y a todos los infrarrealistas- los une una actitud o impronta existencial, la que impacta tanto la cotidianidad del sujeto como su producción poética: una ética. Medina en la introducción identifica al menos cuatro elementos que sostienen esta ética infrarrealista: un antagonismo vital (cita aquí a Renato Poggioli), la fraternidad de la tribu, el placer (también vinculado a la provocación) y, evocando a Mario Santiago, el no hacer de la poesía un oficio que los termine institucionalizando. Fascinante es este último punto. Una de las visiones más enérgicas en la construcción de sentido del Infrarrealismo es precisamente la conciencia y convicción de que la academia literaria es una zona y una práctica discursiva que acaba por oponerse a la poesía. Esta subsumida y radical conciencia, que deviene del discurso poético de Papasquiaro, promueve una sinapsis ética en el grupo, la cual no intenta ser edificante ni coercitiva, lo que se refrenda al apreciar las variantes estéticas del Infrarrealismo, consiguiendo una producción heterogénea y diversa. Esta ética más bien funciona como una brújula, como punto de referencia entre el «delirio y la deriva», alegorías que han hitado la carto- 
grafía infrarrealista; como una voz de la memoria que, a pesar del absoluto grado de libertad, evoca básicos, pero macizos principios del grupo. Escribe Medina: "A los poetas-perros no los mueve la búsqueda de status social, la comodidad sedentaria y consumista, hacer solamente la obra literaria ni la práctica recurrente de crear parcelas de poder en el mundo de la literatura o de otras instituciones de la cultura. El Infrarrealismo no se opone sólo a una tradición poética, sino a todo un sistema real y simbólico de poder literario y cultural".

Luego de la introducción, el libro se divide en diecinueve apartados, cada uno habitado por una voz distinta que a la vez integra esta jauría polifónica, para comenzar a cerrar con un apéndice articulado por dos de los Manifiestos Infrarrealistas (el de Mario Santiago y Bolaño). Ultima la antología un registro fotográfico de infrarrealistas y cercanos que transcurre desde los setentas hasta la actualidad. En relación a los apartados, se citarán versos de cada uno de los autores, sobre todo porque es posible y frecuente sondear textos de altísimo nivel poético, cuya figuración procesual integra: testimonio íntimo, diversidad estética, una política del margen y un discurso ético, tribal. Movilizando un análisis estructural, el texto inicia con José Rosas Ribeyro, poeta peruano expulsado de su país por la Dictadura de Velasco Alvarado y de lacónica estancia en el Infrarrealismo ("La literatura y su ofrecimiento de pequeños puestos en la historia:/ igual a la venta de panteones lujosos en el Distrito Federal./ O una tómbola en la que participo sin fe y sin ganas.”). La irrupción de Santiago Papasquiaro en el segundo apartado trae consigo aquella poesía imposible, escritura que por voluntad propia resbala de un análisis viable que asegure un mínimo cientificismo, poesía que en definitiva intenta reinventar el género, forzarlo y destruirse con él (ella). Inicia el capítulo con los versos: "Callejón sin salida / ayúdanos/ a ensanchar nuestros destinos”. Medina mismo realiza este alcance: el callejón sin salida es uno de los principales cronotropos del Infrarrealismo, agujero negro, proceso, aporía, autorretrato, caparazón que surte de refugio al poeta que, situado ya en la calle de la historia, se hace cargo de su cotidianidad, de su tiempo, pero que requiere de aquel resguardo para no acabar alienado, desvinculado de su intimidad en beneficio de un discurso estrictamente político.

Quien sigue a Papasquiaro es Bolaño. Su apartado se transforma en uno de los gestos más díscolos que se pueda apreciar en una antología: la ins- 
talación de textos fantasmas que re-presentan la ausencia de los versos de Bolaño, espacios en blanco que coinciden con las extensiones de los textos originales y que solo consignan los títulos de los once poemas seleccionados, introducidos por una nota donde Medina explica que si bien la viuda de Bolaño y albacea de su obra, sumada a la «dura custodia» de Anagrama, no cedieron los derechos, igualmente la tribu quiso sumarlo en signo de aprecio y amistad. Entre estos poemas fantasmas está "El burro", texto clave en la poética de Roberto Bolaño y del cual Medina rescata un par de versos que son el epígrafe de esta antología: "En el camino de los perros, allí donde no quiere ir nadie./ Un camino que solo recorren los poetas".

Los apartados se propagan, la antología se organiza cronológicamente, y no son solo materializados poemas, también son prosas, caligramas, versos de: Edgard Artaud Jarry ("Afuera de mi casa se están matando/ escucho el tracatracatraca con eco/ Y yo estoy escribiendo Poemas/ mi mujer grita iPor Dios, deja eso!"), de Víctor Monjarás Ruiz ("Beber/ hasta/ que/ la palabra/ se/ hunda/ en/ su tinta"), de Jorge Hernández Piel Divina ("polvo humo briznas de ternura en esta época/ cuando Karl Marx está muerto/ y hay que ser caníbales-dialécticos racionales-clandestinos/ para que la neurosis no nos bombardee en las calles abandonadas"), de Pedro Damián Bautista ("ahí está la maldita, la inconmensurable/ la inverosímil/ asciende por las fosas nasales e instituciones/ traspasa fronteras en paquetes de rosas, bombones,/ valijas diplomáticas"), de Ramón Méndez Estrada ("los Testigos de Jehová/ predican que está llegando el fin del mundo/ y los marxistas/ que es sólo el comienzo"), del propio Rubén Medina ("I am in all the places/ I want to be/ Mi cuerpo/ es un país/ sin fronteras/ Aquí y aquí/ Estratégicamente viviendo/ Tactickly speaking”), de la poeta Mara Larrosa ("Las mujeres cazadoras, desnudas, antiguas, reposando en los ciervos, ahora podrían/ ser las vietnamitas fecundando el campo, las mujeres que abortan detrás de las barbas."), de José Peguero ("Su corazón es una jaula abierta/ donde beben pájaros vagos e indecentes/ a rienda suelta/ Para escribir poemas los infrarrealistas/ nos encerramos en una jaula parecida."), de Rafael Catana ("Los autos quemados en el desierto/ una noche, un roedor/ el equilibrio de tus párpados/ y mi vocación de incendio."), de Cuauhtémoc Méndez ("Exprimiste gotas de mí/ chorros de sudor y de leche/ bilis, jugos pancreáticos, sangre/ líquido raquídeo, ADN, adrenalina./ Mamaba de tus senos mis ideas; me chupabas por la verga 
la política"), del chileno Bruno Montané ("El estilo es un hospital de tercera/ donde los vagabundos de tu futuro/ cantan una canción de amor/ para los doctores de la academia”), de la argentina Claudia Kerik (“iQué exquisito placer violar las horas sagradas!/ quedarnos toda la noche respirando/ reinventando la manera de acercarnos/ ya no soñar sino vivir el sueño"), de Óscar Altamirano ("ahí la madre ensanchó lo imposible los ojos y pareció lanzar un alarido/ hacia adentro/ alguien más dijo/ además escribe... es poeta... dicen que infrarrealista.../ poeta??!!... gritó el padre... eso jamás!!.../ mi hija nunca va a vivir con un miserable poeta... infra... lo que sea!!..."), de Guadalupe Ochoa ("Madre nuestra que compartes mis entrañas/ y mi cielo/ dame a luz/ alumbra mi camino/ la vida es nuestra/ mi amor es contigo/ bendita eres como todas las mujeres/ Esa muchacha se desangra en un baño público/taladra sus tímpanos el ulular de una sirena"), del chileno Juan Esteban Harrington ("A esta la mataron cuando cabalgaba alimentando crepúsculos/ en noches tan descoloridas/ / más que los galopes de un caballo salvaje -estas eran infinitas/") y de Mario Raúl Guzmán ("BUSCAN MÁS CADÁVERES -cabecean los periódicos/ entre la carga y descarga de pollo fresco").

Perros habitados por las voces del desierto es una antología que incomoda, cuyo vocabulario no ayuda en la regeneración de los lazos del movimiento con la academia (si es que alguna vez los hubo), pues roza lo decididamente insurrecto, aplicando el uso de duros mexicanismos y términos populares y del lumpen puestos al servicio de una escritura académica («chilango», «carnalito», «puta», «cabrona», «¿̇Quién le entra?», entre otros), lo que devela un deseo no solo de provocar, también el de visibilizar una identidad, por parte de Medina, una integración entre el poeta marginado y radical con el respetado académico, lo que a la postre será un gesto consecuente con los principios de esta vanguardia, y que delineará además el ciclo de vuelta de una sutura identitaria. Sin embargo, esta integración de voces y de esta marginalidad/intelectualidad, esta urgencia de unir distintas voces transfronterizas y, por así llamarlas, directrices estéticas, develará una sutura más gruesa. La (re)construcción de identidad de Medina, que queda expuesta -voluntaria o involuntariamente-, abre las capas de las prácticas discursivas de la tribu, también su historicidad: huellas y despliegue de los mecanismos de supervivencia, de su sempiterna alerta frente al poder, parte de las condiciones de producción y de su también sobrevi- 
viente beligerancia. En el ejercicio de Medina, es todo el Infrarrealismo el que insinúa y también manifiesta su proceso identitario. En esta insistente integración de voces y directrices, de centros y márgenes móviles, los poetas infrarrealistas delatan un espíritu inquieto (en su doble acepción), una filosofía de la disidencia, una poética que agrieta el canon, cuyas hendiduras no han sido fáciles de revestir; una revolución que ha transfigurado su lucha, una rebeldía que ha madurado (aunque se advierta aquí un oxímoron), el arrastre de elementos marginales a nuevos espacios del arte, de la literatura y del conocimiento. También de aquella identidad tribal, escribe Medina: "El infrarrealismo propone, en cambio, la aventura, el callejón sin salida, una nueva ética del escritor, el nomadismo, el constante movimiento entre los márgenes y los centros, la crítica y la autocrítica; experiencias todas ellas que deben definir más profundamente a los poetas y la poesía de la época contemporánea".

Como en toda antología, existen inclusiones y exclusiones de parte del seleccionador, quien en esta ocasión explicita los criterios tras las supresiones (de Darío Galicia, Lisa Johnson, Kyra Galván, Vera Larrosa y José Vicente Anaya). Ahora, lo de sumar a Rosas Ribeyro, quien tuvo una estancia más bien breve en el Infrarrealismo y lo de prescindir de Anaya, que fue uno de los articuladores de los primeros manifiestos y uno de los poetas fundadores del Infrarrealismo, son gestos con los que se puede estar o no de acuerdo y los que probablemente ya han generado desacuerdos internos, resistencias intestinales, pero que quizás no han embestido mayormente la cohesión histórica del grupo. No se puede desconocer que tales decisiones proveen de material suficiente para especular y proyectar las batallas futuras del Infrarrealismo, pero finalmente es venturoso el tener la oportunidad de apreciar o intuir los conflictos que se urden en tal o cual movimiento, porque los desidealizan, permitiendo finalmente una crítica desmarcada de condescendencias y teodiceas (a la usanza de Lewis Gordon). Una crítica que permita reconocer las heridas que los distancian y que también los unen, las cicatrices fenomenológicas y lingüísticas, siempre en función del análisis literario. Se puede estar o no de acuerdo, pero el debate inevitablemente reactiva al Infrarrealismo, tensando no solo su diversidad poética, sino también sus estructuras internas, quebrando una cadencia y atizando los discursos y producciones en detrimento de una definición taxativa del grupo. No es difícil, al respecto, el proyectar que nuevas antologías y tex- 
tos críticos acelerarán su paso, problematizando todavía más los orígenes, el despliegue e impacto de esta vanguardia. En aquel escenario, esta antología funcionará ni como piedra filosofal, ni fundacional de una teoría infrarrealista, sino como piedra lanzada en medio de la discusión cultural latinoamericana -y ya no solo «chilanga» ni mexicana-, será pedernal que seguirá partiendo algunos cristales de aquella Torre o Panteón en el que muchas veces quiere (y logra) erigirse la literatura y de paso la crítica literaria. Y el Infrarrealismo -amplificando la voz de Medina y de todos los poetas infra- seguirá incomodando, emancipando sus conceptos, aquellos que la institución desea sosegar y reducir, para complejizar una vez más los fundamentos de esta "poesía en movimiento», de esta vanguardia que, a cuarenta años de su fundación, sigue reinventándose, produciendo, arengando sensibilidades, deliberaciones y, por supuesto, resistencias. 